\title{
Dyes extracted from Trigonella seeds as photosensitizers for dye-sensitized solar cells
}

\author{
Amal Batniji ${ }^{1,2} \cdot$ Monzir S. Abdel-Latif ${ }^{2,3} \cdot$ Taher M. El-Agez ${ }^{1,2}$ Sofyan A. Taya ${ }^{1,2}$ • \\ Hatem Ghamri ${ }^{1,2}$
}

Received: 18 December 2015/ Accepted: 4 June 2016/Published online: 15 June 2016

(c) The Author(s) 2016. This article is published with open access at Springerlink.com

\begin{abstract}
In this paper, the extract of Trigonella seeds was used as sensitizer for dye-sensitized solar cells (DSSCs). The natural dye was extracted from the seeds using water and alcohol as solvents for the raw material. The UV-Vis absorption spectra of Trigonella extract solution and dye adsorbed on $\mathrm{TiO}_{2}$ film were measured. DSSCs sensitized by Trigonella extracted using water as a solvent exhibited better performance with efficiency of $0.215 \%$. The performance of the fabricated DSSCs was attempted to enhance by acid treatment of the FTO substrates with $\mathrm{HNO}_{3}, \mathrm{H}_{3} \mathrm{PO}_{4}$, and $\mathrm{H}_{2} \mathrm{SO}_{4}$. Electrochemical impedance spectroscopy of the fabricated cells was also carried out.
\end{abstract}

Keywords Renewable energy - Solar cells .

Dye-sensitized solar cells $\cdot$ Natural dyes

\section{Introduction}

Nowadays, the world is looking forward for obtaining clean renewable alternative energy source which is essential for developing our current lifestyle and economic growth. This was an inevitable result of the imbalance between the production and consumption of fossil fuel. Solar energy was one of the most promising technologies

Sofyan A. Taya

staya@iugaza.edu.ps

1 Physics Department, Islamic University of Gaza, Gaza, Palestine

2 Renewable Energy Center, Islamic University of Gaza, Gaza, Palestine

3 Chemistry Department, Islamic University of Gaza, Gaza, Palestine that have been extensively studied. The outcome of these studies was construction of three generations of solar cells. The bulk crystalline-silicon solar cell was the first generation which has an acceptable efficiency, but its high cost and industrial requirements led to the second generation known as thin film solar cells. The second generation is cheaper but has low efficiency, so the third generation came to keep the benefits of easy manufacturing and low cost while looking for better converging efficiency. Dyesensitized solar cells (DSSCs) invented by O'Regan and Grätzel [1] are famous by their simple preparation process accompanied with a reasonable efficiency. The main structure of this kind of solar cells is built of a photoactive electrode consisting of a tin-oxide conducting glass mounted by a nanostructured wide band gap metal-oxide semiconductor thin film anchored to suitable dye molecules, which have the ability to be excited by absorbing light photons. The excited electrons are injected from the dye lowest unoccupied molecular orbital (LUMO) to the semiconductor conduction band, passing through an external load to a platinum counter electrode. To complete the circuit the photoactive and the counter electrodes are sandwiched with the space between them is filled by an iodide-triiodide electrolyte. The main rule of the electrolyte is to regenerate the oxidized dye. Conversely, the electrolyte will be regenerated from the counter electrode. Each component of this simple structure has been extensively discussed by many researchers seeking for efficiency improvement. Many wide band gap semiconductors like $\left(\mathrm{TiO}_{2}, \mathrm{ZnO}, \mathrm{SnO}_{2}\right)$ were studied with different morphologies (nanopowder, nanotubes, nanowires) [2-4]. Furthermore, the vital rule for the dye in the working mechanism of DSSCs in light harvesting was investigated. Many chemical groups like homoleptic dyes (N3, N719, N749) developed by Grätzel [5, 6] heteroleptic sensitizers (Z907, 
K19, K77), ruthenium polypyridyl complexes, and organic dyes (triphenylamine, carbazole, phenothiazine) have recorded encouraging efficiencies up to $10-12 \%$. The high cost and environmental harms of these dyes turned the attention toward natural pigments like anthocyanins, chlorophylls, and hypericin [7-9] extracted from plant leaves, roots, flowers, seeds, and fruits [10-16]. In spite of natural dyes low efficiencies compared to ruthenium complexes, they attracted the attention of many researchers working on enhancing their performance by studying the effect of various factors in the extraction process, such as drying, grinding, temperature, anchorage time, and using different compounds of solvents [17, 18]. Natural juglone dye was obtained from the outer shell of walnut fruit by hot extraction method followed by doping using aluminium, copper and iron metals and used as a photosensitizer of DSSCs [19]. Fast production of the $\mathrm{ZnO}$ nanorods by bottom up approach using arc discharge method in deionized water was carried out for DSSC applications [20]. The synthesis of copper-doped polyaniline (NPANI-Cu-X) was performed in many solvents [21]. The obtained PANI was employed as counter electrode in a DSSC configuration. DSSC bilayer design was developed using an $\mathrm{Fe}^{2+}$, $\mathrm{Fe}^{3+}$ (ferrocene) liquid electrolyte and natural dyes extracted from Hypericum perforatum, Rubia tinctorum L. and Reseda luteola [22].

Dye-sensitized solar cells have been prepared using natural dyes such as red cabbage, red perilla, rosella, blue pea, and curcumin [23]. The efficiency of the fabricated DSSCs was improved by selecting a proper sensitizer and modifying the surface of FTO by chemical treatment. The FTO surface was treated by $\mathrm{HCl}$ and $\mathrm{TiCl}_{4}$. Moreover, different organic solvents were used to enhance the extent of sensitization [23].

In this work, the natural dye extracted from Trigonella seeds was studied as a photosensitizer of DSSCs. The absorption spectrum of the extract was determined. The effect of using alcohol and water as solvents of the Trigonella seeds in the dye extraction was investigated. Preacidic treatment to the conductive glass substrates was conducted to improve the DSSC photovoltaic performance. Impedance spectroscopy study was provided to understand the transport of electron and hole carriers, interfacial charge transfer and recombination.

\section{Experimental}

\section{Dye preparation}

The clean dry seeds of Trigonella plant (1st washed with distilled water and dried at $70{ }^{\circ} \mathrm{C}$ ) were grinded by a mortar to form a fine powder. $1 \mathrm{~g}$ of the fine powder was immersed in $5 \mathrm{ml}$ ethyl alcohol at room temperature and left in dark for $24 \mathrm{~h}$, and then the solution was filtered to obtain the final extract solution. The same procedure was repeated for the same amount of Trigonella fine powder but the solvent was replaced with distilled water. Finally, the obtained extracts were kept in dark cold place.

\section{Photoelectrode preparation}

A transparent conducting FTO sheets (resistance 12-14 $\Omega$ / $\mathrm{cm}^{2}$; transmittance: 82-84\%; Xinyan Technology Ltd, Hong Kong) with dimensions $1 \mathrm{~cm} \times 1.5 \mathrm{~cm}$ were cleaned using ultrasonic bath filled with detergent solution for $20 \mathrm{~min}$, then rinsed with distilled water and dried.

The FTO conductive glass sheets were divided into four groups. The first group was not treated by acids. The second, third, and fourth groups were immersed for $10 \mathrm{~min}$ in acid solutions of $\mathrm{HNO}_{3}, \mathrm{H}_{2} \mathrm{SO}_{4}$ and $\mathrm{H}_{3} \mathrm{PO}_{4}$, respectively, each of $0.1 \mathrm{M}$ concentration.

0.2 grams of $\mathrm{TiO}_{2}$ nanopowder ( $\left.\mathrm{P} 25\right)$ was added to $0.1 \mathrm{~g}$ polyethylene glycol and the mixture was grinded for 30 min until a fine paste is obtained.

The $\mathrm{TiO}_{2}$ paste was spread on all the FTO groups by doctor-blade technique, where a thin film was obtained on an area of $0.25 \mathrm{~cm}^{2}$. The sintering process started by drying the sheets at $70{ }^{\circ} \mathrm{C}$ for $20 \mathrm{~min}$, raising temperature to $180{ }^{\circ} \mathrm{C}$ for $10 \mathrm{~min}$, then $450{ }^{\circ} \mathrm{C}$ for $40 \mathrm{~min}$. After cooling down to $70{ }^{\circ} \mathrm{C}$, the $\mathrm{TiO}_{2}$ thin film samples were soaked in the Trigonella natural extract for $24 \mathrm{~h}$ in the dark.

\section{Assembling of DSSC}

The prepared $\mathrm{TiO}_{2}$ photoelectrode (anode) and a conductive glass sheet plated with platinum by electrodeposition (cathode) were sandwiched to assemble the DSSC. Finally, the space between the two electrodes was filled with a liquid electrolyte solution $\left(I^{-} / I_{3}^{-}\right)$composed of $2 \mathrm{ml}$ acetonitrile (ACN), $8 \mathrm{ml}$ propylene carbonate ( $p$-carbonate), $0.668 \mathrm{~g}$ potassium iodide, $\mathrm{KI}$, and $0.0634 \mathrm{~g}$ iodine, $\mathrm{I}_{2}$. Then, the two electrodes were clipped together to form a solar cell ready for light exposure.

\section{Measurement}

The UV-Vis absorption spectra of Trigonella dye extracted by water and alcohol were measured using Thermoline Genesys 6 spectrophotometer with wavelength range extending from 350 to $800 \mathrm{~nm}$. The representative UV-Vis absorption spectrum of the anchored Trigonella extract on $\mathrm{TiO}_{2}$ thin film layer was measured by collecting a diffuse reflectance spectrum with a V-670, JASCO spectrophotometer then transforming it into absorption spectrum according to the Kubelka-Munk relationship. Moreover, 
the cyclic voltammetry was used for the measurement of the HOMO, LUMO, and energy band gap. The current density-voltage $(J-V)$ characteristic curves of the DSSCs under study were measured using National Instruments data acquisition card (USB NI 6251) in combination of a Labview program. An applied voltage in the range between -1 and $1 \mathrm{~V}$ was applied to the illuminated solar cell during current-voltage measurements. The $J-V$ curves were measured at $100 \mathrm{~mW} / \mathrm{cm}^{2}$ irradiations using high pressure mercury arc lamp. Electrochemical impedance spectroscopy (EIS) was carried out using an SP-200 potentiostat (Biologic, USA), with the frequency ranging from $100 \mathrm{~Hz}$ to $200 \mathrm{kHz}$.

\section{Results and discussion}

\section{Absorption spectra}

Trigonella extract UV-Vis absorption spectra in both water and alcohol as solvents are shown in Fig. 1. According to the figure, a clear absorption peak was observed at $400 \mathrm{~nm}$ in case of alcohol and another peak at $444 \mathrm{~nm}$ for water. A diffuse reflectance spectrum was collected for the Trigonella dye adsorbed on $\mathrm{TiO}_{2}$ film and transformed to the absorption spectrum according to the Kubelka-Munk relationship [24], $F(R)=(1-R)^{2} / 2 R=k / s=A c / s$ where $R$ is the reflectance, $k$ is the absorption coefficient, $s$ is the scattering coefficient, $A$ is the absorbance and $c$ is the concentration of absorbing species. When $c$ and $s$ remain the same, the spectrum obtained for Kubelka-Munk function can be considered as absorbance. Figure 2 shows the detected absorption peak at $430 \mathrm{~nm}$ for the dye adsorbed on $\mathrm{TiO}_{2}$ which indicates a red shift towards higher wavelength compared to that of the extract in solution.

The cyclic voltammetry was used for the measurement of the HOMO, LUMO, and energy band gap. It was found

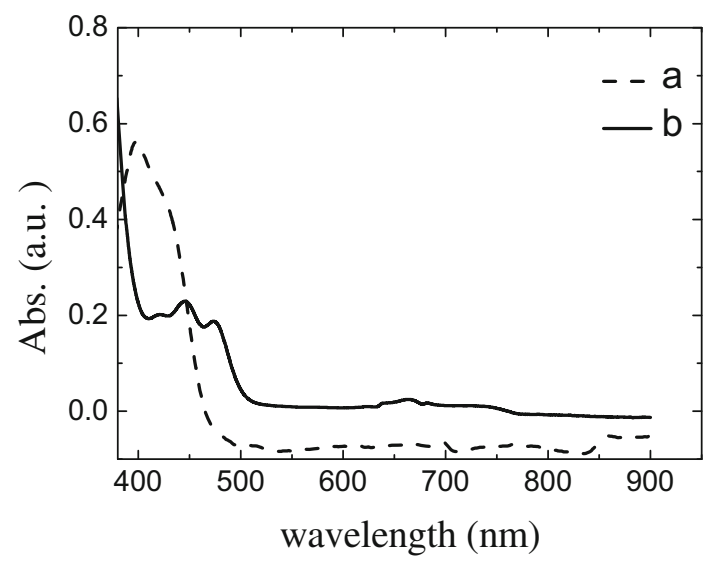

Fig. 1 Light absorption spectra of Trigonella extract dye solution using $a$ alcohol and $b$ water

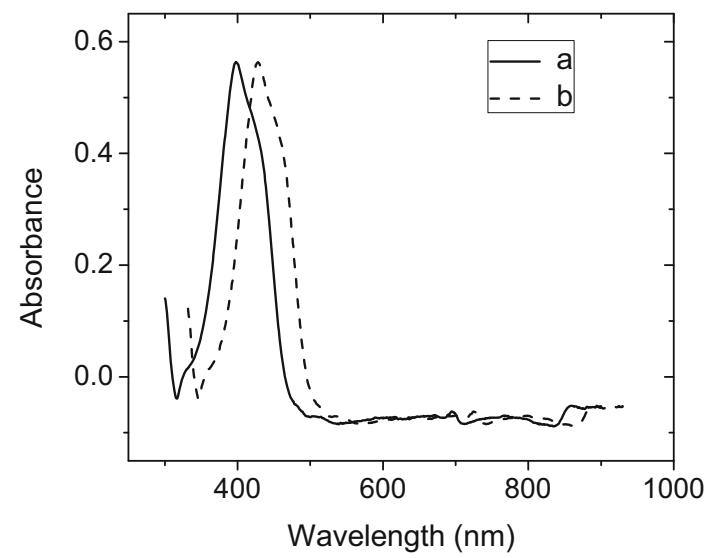

Fig. $2 a$ Light absorption spectra of Trigonella extract dye solution using alcohol and $b$ dye adsorbed on $\mathrm{TiO}_{2}$

that $E_{\mathrm{HOMO}}=6.28 \mathrm{eV}, \quad E_{\mathrm{LUMO}}=3.75 \mathrm{eV}$ and $E_{\mathrm{opt}}=$ $2.5 \mathrm{eV}$.

\section{Photovoltaic properties}

The $J-V$ characteristic curves for DSSCs (fabricated using untreated FTO, 1st group,) sensitized by the natural extract of Trigonella seeds using water and alcohol as solvents are illustrated in Fig. 3. The main photoelectrochemical parameters obtained from Fig. 3 are listed in Table 1. These parameters are short circuit current $J_{\mathrm{sc}}$, open circuit voltage $V_{\mathrm{oc}}$, fill-factor FF, and conversion efficiency $\eta$. It is clear from the figure that the performance of DSSCs sensitized by Trigonella extracted using water as a solvent is much better than that of solar cells sensitized by Trigonella extracted with alcohol. Referring to Table 1, $J_{\mathrm{sc}}=0.371 \mathrm{~mA} / \mathrm{cm}^{2}$ with alcohol and $J_{\mathrm{sc}}=0.747 \mathrm{~mA} /$ $\mathrm{cm}^{2}$ with water giving $201 \%$ improvement. On the other hand, $V_{\mathrm{oc}}=0.599 \mathrm{~V}$ and $\mathrm{FF}=48 \%$ with alcohol are almost the same as $V_{\mathrm{oc}}=0.601 \mathrm{~V}$ and $\mathrm{FF}=48 \%$ with

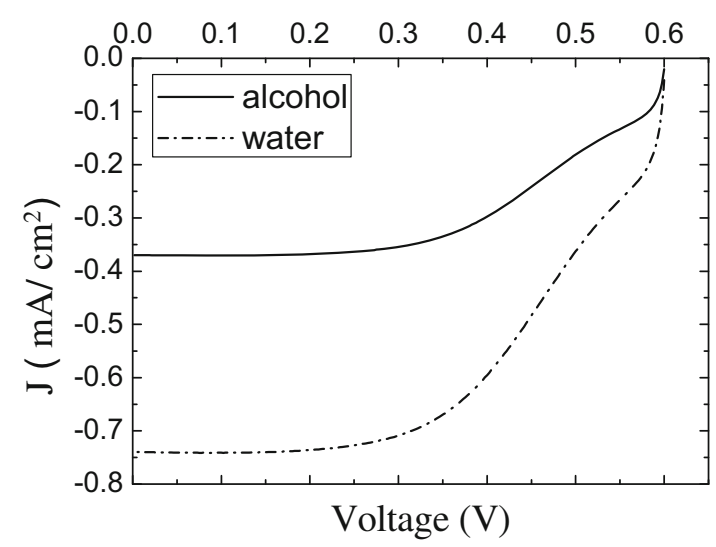

Fig. 3 Current density-voltage curves for the DSSCs sensitized by Trigonella seeds dye using alcohol and water as solvents 
Table 1 Photoelectrochemical parameters of DSSCs sensitized by Trigonella seeds dye

\begin{tabular}{lllll}
\hline Solvent & $J_{\mathrm{sc}}\left(\mathrm{mA} / \mathrm{cm}^{2}\right)$ & $V_{\mathrm{oc}}(\mathrm{V})$ & $\mathrm{FF}(\%)$ & $\eta(\%)$ \\
\hline Alcohol & 0.371 & 0.599 & 48 & 0.106 \\
Water & 0.747 & 0.601 & 48 & 0.215 \\
\hline
\end{tabular}

water, which means that the raise in efficiency from $\eta=0.106 \%$ with alcohol up to $\eta=0.215 \%$ with water leading to $202.8 \%$ improvement is due to the significant improvement in the short circuit current. It is worth mentioning that the extracts of water are different from those of alcohol. The current improvement can be attributed to the extracts of water.

\section{Acidic treatment of FTO sheets}

The DSSCs used in this treatment were sensitized with the natural extract of Trigonella seeds using water as a solvent. The $J-V$ characteristic curves of DSSCs fabricated using untreated FTO (1st group) and those prepared using acid treated FTO (2nd, 3rd, and 4th groups) are plotted in Fig. 4. Their photoelectrochemical parameters are listed in Table 2. According to the $J-V$ curves we can notice that the FTO treatment with $\mathrm{HNO}_{3}$ and $\mathrm{H}_{3} \mathrm{PO}_{4}$ acids gave better performance than untreated cells. From Table 2, the treatment with $\mathrm{HNO}_{3}$ gave a short circuit current $J_{\mathrm{sc}}=0.840 \mathrm{~mA} / \mathrm{cm}^{2}, V_{\mathrm{oc}}=0.641 \mathrm{~V}$, and $\eta=0.259 \%$, leading to an improvement by $112.5,106.6$, and $120.4 \%$, respectively, over the untreated cells. On the other hand, the enhancements in case of $\mathrm{H}_{3} \mathrm{PO}_{4}$ were only $101.2 \%$ for $J_{\mathrm{sc}}$ and $100.9 \%$ for $V_{\mathrm{oc}}$. This improvement is due to better adhesion of the $\mathrm{TiO}_{2}$ layer to the FTO, which means reducing the resistivity for high charge transport leading to higher short-circuit current density.

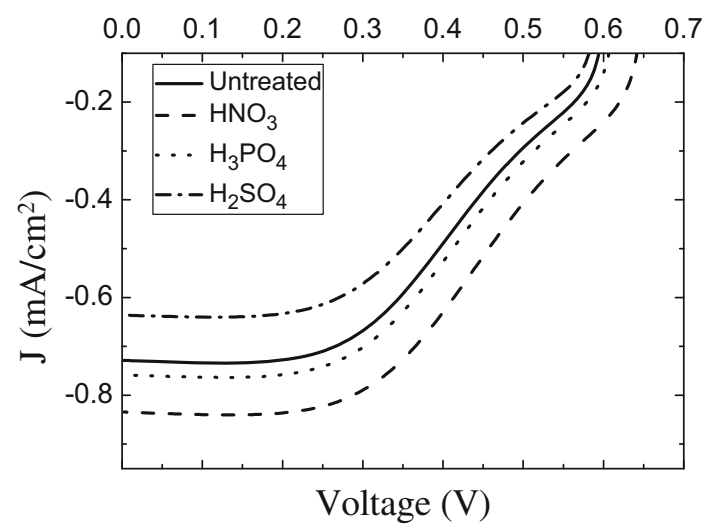

Fig. 4 Current density-voltage curves for the DSSCs sensitized by Trigonella using untreated and acid treated FTO substrates
Table 2 Photoelectrochemical parameters of the DSSCs sensitized by Trigonella using untreated and acid treated FTO substrates

\begin{tabular}{lllll}
\hline Acid & $J_{\text {sc }}\left(\mathrm{mA} / \mathrm{cm}^{2}\right)$ & $V_{\text {oc }}(\mathrm{V})$ & FF $(\%)$ & $\eta(\%)$ \\
\hline No-treatment & 0.747 & 0.601 & 48 & 0.215 \\
$\mathrm{HNO}_{3}$ & 0.840 & 0.641 & 48 & 0.259 \\
$\mathrm{H}_{3} \mathrm{PO}_{4}$ & 0.756 & 0.607 & 49 & 0.226 \\
$\mathrm{H}_{2} \mathrm{SO}_{4}$ & 0.638 & 0.580 & 48 & 0.179 \\
\hline
\end{tabular}

Impedance spectroscopy measurements

The solar cells sensitized with the extract of Trigonella seeds were perturbed by a small AC voltage signal of amplitude $10 \mathrm{mV}$ with varying frequency $(100 \mathrm{~Hz}$ to $200 \mathrm{kHz}$ ), to carry out an EIS study. This EIS study was employed to figure out the charge transport kinetics through the analysis of the Nyquist and Bode plots shown in Figs. 5 and 6, respectively. The main parameters calculated from the curves are the charge recombination resistance $R_{\mathrm{S}}$, the charge transfer resistance $R_{\mathrm{CT}}$, double layer capacitance $\left(C_{\mathrm{dl}}\right)$, the constant phase element CPE $(\alpha)$ due to double layer capacitance, and the effective lifetime of electrons $\tau$. All these parameters were calculated and summarized in Table 3. As can be seen from the table, $R_{\mathrm{S}}=31 \Omega$ which is small enough for fast electron transport, in the same context a very large $R_{\mathrm{CT}}=7,204 \Omega$ indicates long lifetime $(62.5 \mathrm{~ms})$ for the electrons in the film. The CPE coefficient $\alpha=0.76$ illustrates electrode surface roughness accompanied with complicated structure double layer capacitance.

\section{Conclusions}

The extract of Trigonella seeds as a natural sensitizer was used in the preparation of DSSCs. Two different solvents (alcohol and water) were used in the extraction process of

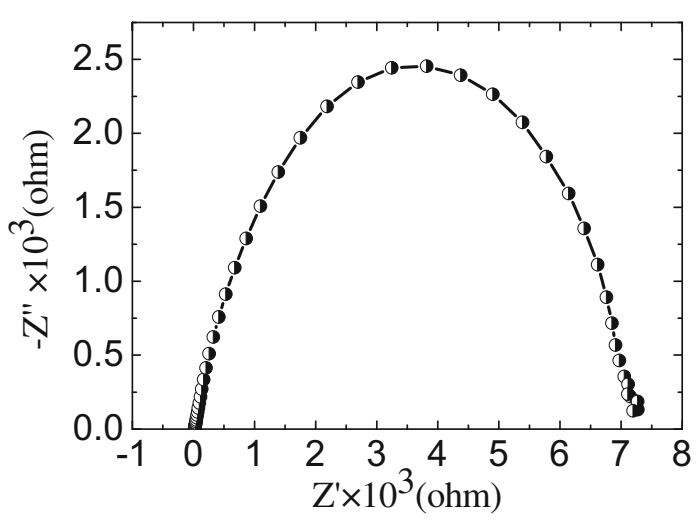

Fig. 5 EIS Nyquist plots of DSSCs sensitized by Trigonella under an illumination of $100 \mathrm{~mW} / \mathrm{cm}^{2}$ and applied voltage of $-0.7 \mathrm{~V}$ 
Fig. 6 Bode plots of DSSCs sensitized by Trigonella under an illumination of $100 \mathrm{~mW} / \mathrm{cm}^{2}$ and applied voltage of $-0.7 \mathrm{~V}$
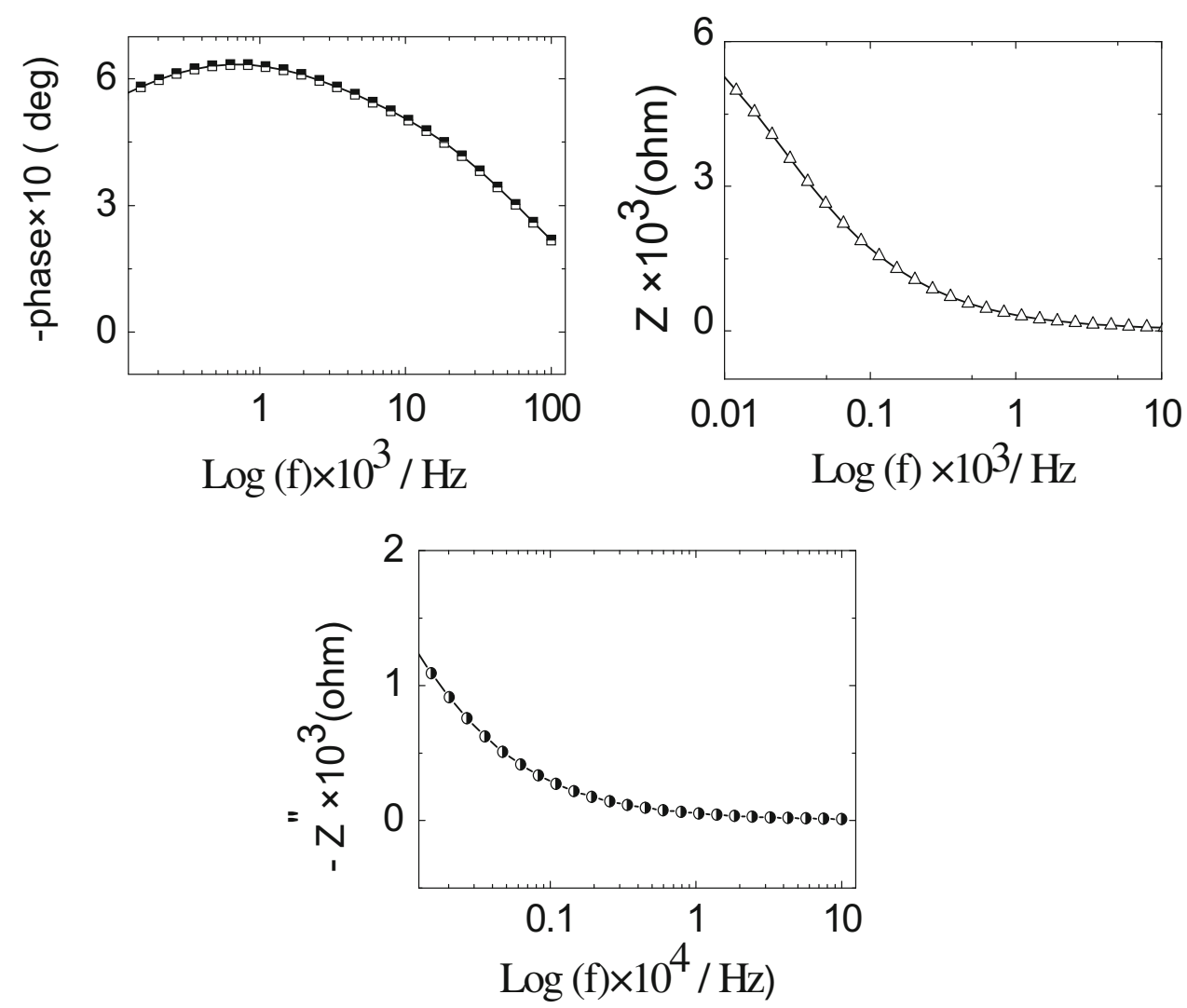

Table 3 The impedance spectroscopy parameters of the DSSCs sensitized by Trigonella

\begin{tabular}{lllll}
\hline$R_{\mathrm{S}}(\Omega)$ & $R_{\mathrm{CT}}(\Omega)$ & $C_{\mathrm{dl}}(\mu \mathrm{F})$ & $\alpha(\mathrm{CPE}$ coefficient $)$ & $\tau(\mathrm{ms})$ \\
\hline 31 & 7,204 & 8.676 & 0.76 & 62.5 \\
\hline
\end{tabular}

the dye from the raw material. The highest conversion efficiency of $0.215 \%$ (with water as a solvent) compared to $0.106 \%$ (with alcohol as a solvent) was obtained for the fabricated DSSC. A pre-treatment process for the FTO glass substrates with acidic solutions led to an efficiency improvement in case of $\mathrm{HNO}_{3}$ and $\mathrm{H}_{3} \mathrm{PO}_{4}$. Impedance spectroscopy study for the fabricated solar cells was obtained from the analysis of the Nyquist and Bode plots, and the most important parameters like charge recombination resistance $R_{\mathrm{S}}$, charge transfer resistance $R_{\mathrm{CT}}$, constant phase element CPE due to double layer capacitance $\left(C_{\mathrm{dl}}\right)$, and effective lifetime of electrons $\tau$ were determined.

Acknowledgments The authors would like to express gratitude to the ministry of higher education for the financial support of this work.

Open Access This article is distributed under the terms of the Creative Commons Attribution 4.0 International License (http://creative commons.org/licenses/by/4.0/), which permits unrestricted use, distribution, and reproduction in any medium, provided you give appropriate credit to the original author(s) and the source, provide a link to the Creative Commons license, and indicate if changes were made.

\section{References}

1. O'Regan, B., Grätzel, M.: A low-cost, high-efficiency solar cell 737-740 (1991)

2. Roy, M., Balraju, P., Kumar, M., Sharma, G.: Dye-sensitized solar cell based on rose bengal dye and nanocrystalline $\mathrm{TiO}_{2}$. Sol. Energy Mater. Sol. Cells 92, 909-913 (2008)

3. Gubbala, S., Chakrapani, V., Kumar, V., Sunkara, M.K.: Band-edge engineered hybrid structures for dye-sensitized solar cells based on $\mathrm{SnO}_{2}$ nanowires. Adv. Funct. Mater. 18, 2411-2418 (2008)

4. El-Agez, T., El Tayyan, A., Al-Kahlout, A., Taya, S., AbdelLatif, M.: Dye-sensitized solar cells based on $\mathrm{ZnO}$ films and

5. Grätzel, M.: Dye-sensitized solar cells. J. Photochem. Photobiol. C Photochem. Rev. 4, 145-153 (2003)

6. Grätzel, S.: Solar energy conversion by dye-sensitized photovoltaic cells. Inorg. Chem. 44, 20-28 (2005)

7. Dai, O., Rabani, I.: Photosensitization of nanocrystalline $\mathrm{TiO}_{2}$ films by anthocyanin dyes. J. Photochem. Photobiol. A Chem. 26, 421-429 (2002)

8. Changa, H., Wu, H., Chen, T., Huang, K., Jwo, C., Lo, Y.: Dyesensitized solar cell using natural dyes extracted from spinach and ipomoea. J. Alloys Compd. 495, 606-610 (2010)

9. Wongcharee, K., Meeyoo, V., Chavadej, S.: Dye-sensitized solar cell using natural dyes extracted from rosella and blue pea flowers. Sol. Energy Mater. Sol. Cells 91, 566-571 (2007)

10. Abdel-Latif, M., Abuiriban, M., El-Agez, T., Taya, S.: Dye-sensitized solar cells using dyes extracted from flowers, leaves, parks, and roots of three trees. Int. J. Renew. Energy Res. 5, 294-298 (2015)

11. El-Ghamri, H., El-Agez, T., Taya, S., Abdel-Latif, M., Batniji, A.: Dye-sensitized solar cells with natural dyes extracted from plant seeds. Mater. Sci. Pol. 32, 547-554 (2015) based on dye-sensitized colloidal $\mathrm{TiO}_{2}$ films. Nature 353, natural dyes. Int. J. Mater. Chem. 2, 105-110 (2012) 
12. Taya, S., El-Agez, T., El-Refi, K., Abdel-Latif, M.: Dye-sensitized solar cells based on dyes extracted from dried plant leaves. Turk. J. Phys. 39, 24-30 (2015)

13. Calogero, G., Marco, G.: Red Sicilian orange and purple eggplant fruits as natural sensitizers for dye-sensitized solar cells. Sol. Energy Mater. Sol. Cells 92, 1341-1346 (2008)

14. Batniji, A., Morjan, R., Abdel-Latif, M., El-Agez, T., Taya, S., El-Ghamri, H.: Aldimine derivatives as photosensitizers for dyesensitized solar cells. Turk. J. Phys. 38, 86-90 (2014)

15. Taya, S., El-Agez, T., Abdel-Latif, M., El-Ghamri, H., Batniji, A., El-Sheikh, I.: Fabrication of dye-sensitized solar cells using dried plant leaves. Int. J. Renew. Energy Res. 4, 384-388 (2014)

16. El-Agez, T., Taya, S., ElRefi, K., Abdel-Latif, M.: Dye sensitized solar cells using some organic dyes as photosensitizers. Optica Applicata 44, 345-351 (2014)

17. Hemmatzadeh, H., Mohammadi, A.: Improving optical absorptivity of natural dyes for fabrication of efficient dye-sensitized solar cells. J. Theor. Appl. Phys. 7, 57-65 (2013)

18. Dumbravă, A., Enache, I., Oprea, C., Georgescu, A., Gîrțu, M.: Toward a more efficient utilization of betalains as pigments for dye-sensitized solar cell. Dig. J. Nanomater. Biostruct. 7, 339-351 (2012)
19. Sönmezoğlu, S., Akyürek, C., Akış, H.: Modification of juglone dye as a sensitiser in dye-sensitised solar cells. IET Optoelectron. 8, 270-276 (2014)

20. Sönmezoğlua, S., Eskizeybekb, V., Toumiatc, A., Avcıd, A.: Fast production of $\mathrm{ZnO}$ nanorods by arc discharge in de-ionized water and applications in dye-sensitized solar cells. J. Alloys Compd. 586, 593-599 (2014)

21. Recep, T., Mahir, G., Muzaffer, C., Sönmezoğlu, S.: Effects of solvent and copper-doping on polyaniline conducting polymer and its application as a counter electrode for efficient and costeffective dye-sensitized solar cells. Synth. Met. 212, 75-83 (2015)

22. Sönmezoğlu, S., Akyurek, C., Akin, S.: High-efficiency dyesensitized solar cells using ferrocene-based electrolytes and natural photosensitizers. J. Phys. D Appl. Phys. 45, 425101 (2012)

23. Sreekala, C., Jinchu, I., Sreelatha, K., Janu, Y., Prasad, N., Kumar, M., Sadh, A., Roy, M.: Influence of solvents and surface treatment on photovoltaic response of DSSC based on natural curcumin dye. IEEE J. Photovolt. 2, 312-319 (2012)

24. Shen, J., Li, Y., He, J.: On the Kubelka-Munk absorption coefficient. Dyes Pigments 127, 187-188 (2016) 